\title{
Adverse Effects of Mega Dose of Vitamin A Administration--A need for Introspection
}

\author{
Prof. Umesh Kapil (corresponding author) \\ Professor and Head \\ Department of Gastroenterology and Human Nutrition \\ All India Institute of Medical Sciences, \\ New Delhi, India \\ Email: umeshkapil@gmail.com \\ Dr. Neha Sareen \\ Research Scientist \\ Department of Gastroenterology and Human Nutrition \\ All India Institute of Medical Sciences, \\ New Delhi, India \\ Email: nehasareen088@gmail.com
}

\section{Intro duction}

Vitamin A (VA) is an essential nutrient needed in small amounts for the normal functioning of the visual system, growth and development, maintenance of epithelial cellular integrity, immune function and reproduction. Severe deficiency of VA is known to produce corneal xerophthalmia, keratomalacia and blindness in children (1).

In the 1950s and 1960s, an unacceptably high magnitude of xerophthalmic blindness was found in India (2) and in view of this, in 1970, the National Prophylaxis Programme against Nutritional Blindness (NPPNB) due to Vitamin A Deficiency (VAD) was started with the objective of preventing nutritional blindness. Under this programme, young children were given megadose of vitamin A (MDVA) every six months. Each child received five doses of VA before her/his $3^{\text {rd }}$ birthday (children age 6-11 months, 1 dose of 100,000 IU of VA and in age 12-36 months of age one dose of 200,000 IU of VA every six months) (3).

The NPPNB is still continuing, expanded to all under five children, for two possible objectives: i) Reduction in under five mortality and ii) Prevention of nutritional blindness due to VAD.

An analysis of the data available from NFHS-4 suggests that a very small proportion of deaths are occurring in young children in the age group of 6-59 months. The difference between Under five mortality rate and Infant mortality rate is in the range of one to eight points in different states of the country and hence probably Vitamin A supplementation (VAS) may not have much impact in reducing under five mortality (Table 1) (4). Also,during last 50 years, clinical VAD has declined. Nutritional blindness due to VAD has virtually disappeared due to i) Increases in immunization coverage (leading to decreases in measles) ii) Increases in the use of antibiotics (leading to reduced duration of morbidity due to bacterial respiratory diseases) iii) Increases in use of ORS (leading to prevention of mortality due to diarrhoea) iv) Improved health infrastructure v) Increase in exclusive breastfeeding vi) 
Improvements in diets of young children vii) A significant reduction in severe forms of protein energy malnutrition (5).

To control VAD, large therapeutic doses are still being administered in developing countries to lactating women and children (6).

Table 1: Infant mortality rate and under five mortality rate in India (4)

\begin{tabular}{|c|c|c|c|c|}
\hline S.No. & State & $\begin{array}{l}\text { Under five } \\
\text { mortality } \\
\text { rate per } \\
1000 \text { live } \\
\text { births }\end{array}$ & $\begin{array}{l}\text { Infant } \\
\text { Mortality } \\
\text { Rate per } \\
1000 \text { live } \\
\text { births }\end{array}$ & $\begin{array}{l}\text { Difference } \\
\text { between U5MR } \\
\text { and IMR }\end{array}$ \\
\hline & India & 50 & 41 & 9 \\
\hline & & & & \\
\hline & Group A states & & & \\
\hline 1. & Daman and Diu & 34 & 34 & 0 \\
\hline 2. & Goa & 13 & 13 & 0 \\
\hline 3. & Puducherry & 16 & 16 & 0 \\
\hline 4. & Kerala & 7 & 6 & 1 \\
\hline 5. & Andaman \& Nicobar & 13 & 10 & 3 \\
\hline 6. & Sikkim & 32 & 29 & 3 \\
\hline 7. & Himachal Pradesh & 38 & 34 & 4 \\
\hline 8. & Karnataka & 32 & 28 & 4 \\
\hline 9. & Lakshadweep & 23 & 19 & 4 \\
\hline 10. & Manipur & 26 & 22 & 4 \\
\hline 11. & Punjab & 33 & 29 & 4 \\
\hline 12. & Telangana & 32 & 28 & 4 \\
\hline 13. & Maharashtra & 29 & 24 & 5 \\
\hline \multirow[t]{2}{*}{14.} & West Bengal & 32 & 27 & 5 \\
\hline & Group B states & & & \\
\hline 15. & Andhra Pradesh & 41 & 35 & 6 \\
\hline 16. & Jammu and Kashmir & 38 & 32 & 6 \\
\hline 17. & Mizoram & 46 & 40 & 6 \\
\hline 18. & Tamil Nadu & 27 & 21 & 6 \\
\hline 19, & Tripura & 33 & 27 & 6 \\
\hline 20. & Uttarakhand & 47 & 40 & 7 \\
\hline 21. & Assam & 56 & 48 & 8 \\
\hline 22. & Haryana & 41 & 33 & 8 \\
\hline 23. & Nagaland & 37 & 29 & 8 \\
\hline 24. & Dadra and Nagar Haveli & 42 & 33 & 9 \\
\hline 25. & Gujarat & 43 & 34 & 9 \\
\hline 26. & Odisha & 49 & 40 & 9 \\
\hline 27. & Arunachal Pradesh & 33 & 23 & 10 \\
\hline 28. & Bihar & 58 & 48 & 10 \\
\hline 29. & Chhattisgarh & 64 & 54 & 10 \\
\hline 30. & Jharkhand & 54 & 44 & 10 \\
\hline 31. & Meghalaya & 40 & 30 & 10 \\
\hline
\end{tabular}




\begin{tabular}{|l|l|l|l|l|}
\hline 32. & Rajasthan & 51 & 41 & 10 \\
\hline 33. & Delhi NCT & 47 & 35 & 12 \\
\hline 34. & Madhya Pradesh & 65 & 51 & 14 \\
\hline 35. & Chandigarh & $*$ & $*$ & $*$ \\
\hline
\end{tabular}

*Data not available

\section{Adverse Effects of MDVA}

In this research communication, we would like to share the existing knowledge and evidence with the readers of journal of World Public Health Nutrition Association that there are adverse effects of administration of MDVA which are not known to the health and nutrition functionaries who supervise and or administer MDVA and hence they are unable to identify these adverse effects and report them.

Research on vitamin A toxicity has been primarily carried out in animals. Most studies have been short term and have focussed on acute effects (7-9). Many studies are not relevant because they used intramuscular or venous injections of various forms of vitamin A (10-11), which cannot be extrapolated to physiologic conditions in children because injections bypass gastrointestinal effects. MDVA administered to children provides high doses, and is dealt by the body as a toxin, not as a nutrient. Serum levels rise to normal or above normal levels only for 1-3 months (12).

\section{Effect of MDVA on Congenital abmormalities}

Congenital abnormalities have been reported amongst pregnant mothers (PMs) The ratio of the prevalence of congenital malformation among the babies born to women who consumed vitamin A supplements of more than 10,000 IU per day to that among the babies whose mothers consumed 5000 IU or less per day was 4.8 (95 \% CI, 2.2 to 10.5) (13).

\section{Effect of MDVA on bulging fontanelle}

A significant proportion of brain development takes place before 3 years of age. The development of the brain is not complete at birth, and the first 12 months are crucial. The impact of prolonged increased intra-cranial tension on brain development is not known. During infancy billions of brain cells are developing and as many as 6,000 to 10,000 synaptic connections are established between each neural cell, which determines behaviour and overall mental development (14).

A study conducted in Bangladesh, reported that one hundred and sixty-seven infants received three doses of either $25000 \mathrm{IU}$ of vitamin A $(n=86)$ or a placebo $(n=81)$ at about $6.5,11.8$ and 17.0 weeks of age. Nine infants (10.5\%) supplemented with vitamin A had episodes of bulging of the fontanelle compared with two infants $(2.5 \%)$ in the placebo group ( $p<0.05$, chi square test). In total, there were 14 episodes of bulging of the fontanelle, 12 of which occurred in infants supplemented with vitamin A. Thus, the incidence of bulging of the fontanelle was $4.7 \%$ following vitamin A supplementation compared with $0.8 \%$ with placebo ( $\mathrm{p}<0.05$, chi-square test) (15).

However, a recent study conducted in Bangladesh reported that general intelligence or memory and motor functions were not affected by antenatal or newborn supplementation 
with vitamin A. Scholastic performance and aspects of executive function improved with vitamin A supplementation (16).

Another study was conducted on impact of neonatal vitamin A supplementation on development and growth at $3 \mathrm{y}$ of age. It was found that vitamin A supplementation or a bulging fontanelle had no link with cognitive performance at age 3 years (17).

In India, nearly $22 \%$ of births are low birth weight (18). Subjecting these low birth weight children to repeated episodes of increased intracranial tension could possibly contribute to retarded brain development. Systematic investigations have not been undertaken to assess the impact of bulging fontanelle during infancy on the development of brain.

\section{Effect of MDVA on Respiratory Infection}

A meta-analysis of 9 randomised controlled trials enrolling 33,179 children up to 7 years of age who were given mega dose of 100,000 to 200,000 IU of vitamin A with lower respiratory tract infections, concluded that vitamin A supplementation was not helpful for preventing pneumonia, at least in normally nourished children, and might rather worsen the situation; it slightly increased the incidence of respiratory tract infections. The meta-analysis concluded that there is no consistent overall protective effect on the incidence of diarrhoea (19).

Another study conducted amongst children reported that vitamin A administration was associated with a significant increase in the rate of pneumonia in well-nourished children who received 10,000 IU of vitamin A supplements weekly (20).

Prolonged high dose administration is known to be toxic. An example is a case study in which a child of 3 year who was administered with 100,000 IU/d for a week and then 50,000 IU/d for 6 months developed ascites with respiratory distress (21).

\section{Effect of MDVA on bone health}

Animal studies suggest that vitamin A is a potential antagonist of vitamin D. Massive doses of vitamin A intensifies the severity of bone demineralisation. Increasing amounts of retinyl acetate produce progressive and significant decrease in total bone ash and increase in epiphyseal plate width. Increasing the levels of retinyl acetate abrogates the ability of vitamin $\mathrm{D}$ to elevate the level of serum calcium (22-24).

A case control study conducted in women of 28-74 years old found that retinol intake was negatively associated with bone mineral density. For every $1 \mathrm{mg}$ (3000 IU) increase in daily intake of retinol, risk for hip fracture increased by $68 \%$. High dietary intake of retinol was considered to be associated with osteoporosis (25).

Another study conducted amongst postmenopausal women aged 34 to 77 years reported that women in the highest quintile of total vitamin A intake $(\geq 3000 \mathrm{mcg} / \mathrm{d}$ of retinol equivalents (RE) had a significantly elevated relative risk (RR) of hip fracture (RR, 1.48; 95\% confidence interval [CI], 1.05-2.07; P for trend $=.003$ ) compared with women in the lowest quintile of intake $(<1250 \mathrm{mcg} / \mathrm{d}$ of RE). This increased risk was attributable primarily to retinol (RR, 1.89; 95\% CI, 1.33-2.68; P for trend $<0.001$ comparing $\geq 2000 \mathrm{mcg} / \mathrm{d}$ vs $<500 \mathrm{mcg} / \mathrm{d})$ (26).

Animal studies have also reported the importance of vitamin A in the bone remodelling process (27-29). Vitamin A deficiency resulted in retarded bone growth, but the most 
prominent features of hypervitaminosis A was accelerated bone resorption (28), bone fragility and spontaneous fracture (29). Toxic doses of retinoids have been reported to produce musculoskeletal symptoms (such as pain, tenderness and stiffness of muscles or joints) and neurological symptoms (including fatigue, headaches and dizziness) that may influence the occurrence of fracture (30).

Arctic populations who consumed high quantities of preformed vitamin A have reported reduced bone mineral density and increased risk for hip fracture (31-32).

Several studies have suggested an association between chronic high intakes of preformed vitamin A and bone loss (26, 33-36). Hypercalcemia and elevated alkaline phosphatise, in persons with vitamin A toxicity has been found, suggesting that vitamin A affects bone (6).

Long term use of vitamin A at doses greater than 50,000 units per day causes hypercalcemia, possibly due to a direct effect on bone (37). The effect of MDVA in children who are stunted and deficient in vitamin D needs to be investigated.

\section{Serious Adverse effects of MDVA Supplementation}

In Assam, high dose of vitamin A supplementation to children was administered up to 500,000 IUs to children between one and five years of age. Fourteen children died and 953 children had serious symptoms of vitamin A toxicity and needed hospitalisation (38).

\section{The Way Forward}

In India, the universal supplementation of MDVA (200,000 IU) is being undertaken to all children irrespective of their vitamin A status. The RDA of vitamin A for young children is $1333 \mathrm{IU}$ (400 mcg). MDVA provides a dose of vitamin A which is 150 times this RDA. It is thus not a nutritional or physiological dose but a pharmacological dose. Actual and potential adverse effects of giving pharmacological doses of vitamin A to young children, including the majority of children with no signs of deficiency is a cause of concern due attention should be accorded by researchers, health planners and policy makers.

It is a known fact that the thrust for VAS is partly fuelled by international agencies (39), based on the argument that the dietary intake of vitamin $\mathrm{A}$ in young children is inadequate and hence MDVA is expected to improve their vitamin A status. We make a plea for careful and meticulous investigation of adverse effects of MDVA administration.

There is a need to generate the evidence on adverse effects of MDVA and we should look for these effects more vigilantly.

A country struggling with economic resources for competing public health programmes should not embark on exercise of universal VA supplementation for which there is poor evidence of functional benefits (reduction in under five mortality and prevention of nutritional blindness) while possibly associated with adverse effects. 


\section{References}

1. WHO 2014. Xerophthalmia and night blindness for the assessment of clinical vitamin A deficiency in individuals and populations. Vitamin and Mineral Nutrition Information System. Geneva: World Health Organization (WHO/NMH/NHD/EPG/14.4); http://apps. who.int/iris/bitstream/10665/133705/1/WHO_NMH_NHD_ EPG_14.4_eng.pdf?ua=1, accessed 2306 17)

2. Kapil U, Chaturvedi S, Nayar D. 1992. National nutrition supplementation programmes. Indian Pediatr 29: 1601-13.

3. Maternal and child health scheme for prophylaxis against nutritional blindness in children caused by vitamin A deficiency. Family Planning Programme, Fourth FiveYear Plan Technical Information. New Delhi: Government of India Press; 1970: MCH No. 2; pp. 1-22.

4. International Institute for Population Sciences. National Family Health Survey (NFHS-4): India. Mumbai: IIPS; 2015-2016.

5. Kapil U, Gupta A. 2016. Low-quality scientific evidence for the continuation of universal Vitamin A supplementation among under 5 children in India. Indian Journal of Public Health 60: 176-180.

6. Penniston KL, Tanumihardjo SA. 2006. The acute and chronic toxic effects of vitamin A. Am J Clin Nutr 83: 191-201.

7. Weigand UW, Hartmann S, Hummler H. 1998. Safety of vitamin A: recent results. Int J Vitam Nutr Res 68: 411-416.

8. Collins MD, Mao GE. 1999. Teratology of retinoids. Annu Rev Phasmacol Toxicol39: 399-430.

9. Adamson PC, Murphy RF, Godwin KA, et al. 1995. Pharmacokinetics of 9-cisretinoic acid in the rhesus monkey. Cancer Res 55: 482-485.

10. Mecapinlac MP, Olson JA. 1981. A lethal hypervitaminosis A syndrome in young monkeys (Macacus fascicularis) following a single intramuscular dose of a watermiscible preparation containing vitamins A, D2 and E. Int J Vitam Nutr Res 51: 331341.

11. Allen LH, Haskel M. 2002. Estimating the potential for vitamin A toxicity in women and young children. J Nutr 132: 2907S-19S.

12. Mason J, Greiner T, Shrimpton R, et al. 2015. Vitamin A policies need rethinking. International Journal of Epidemiology; 283-292.

13. Rothman KJ, Moore LL, Singer MR, et al. 1995. Teratogenicity of high vitamin A intake. N Engl J Med 333: 1369-73.

14. Gopalan C. Toxic effects of administration of synthetic vitamin A to children under three years of age.

15. Baqui AH, de Francisco A, Arifeen SE, et al. 1995. Bulging fontanelle after supplementation with 25,000 IU of vitamin A in infancy using immunization contacts. Acta Paediatr 84(8):863-866.

16. Ali H, Hamadani J, Mehra S, et al. 2017. Effect of Maternal Antenatal and Newborn Supplementation with Vitamin A on Cognitive Development of School-Aged Children in Rural Bangladesh: A Follow-Up of a Placebo-controlled, Randomized Trial. Am J Clin Nutr. (http://ajcn.nutrition.org/content/early/2017/05/10/ajcn.116.134478.abstract) 
17. Humphrey JH, Agoestina T, Juliana A, et al. 1998. Neonatal vitamin A supplementation: effect on development and growth at 3 y of age. Am J Clin Nutr 68(1):109-17.

18. Arnold F, Parasuraman S, Arokiasamy P, et al. 2009. Nutrition in India. National Family Health Survey (NFHS-3), India, 2005-06. Mumbai: International Institute for Population Sciences; Calverton, Maryland, USA: ICF Macro.

19. Stansfield SK, Pierre-Louis M, Lerebours G, et al. 1993. Vitamin A supplementation and increased prevalence of childhood diarrhoea and acute respiratory infections. Lancet 342:578-82.

20. Sempertegui F, Estrella B, Camaniero V, et al. 1999. The beneficial effects of weekly low-dose vitamin A supplementation on acute lower respiratory infections and diarrhea in Ecuadorian children. Pediatrics 104: e1.

21. Mendoza FS, Johnson F, Kerner JA, et al. 1988. Vitamin A Intoxication Presenting With Ascites and a Normal Vitamin A Level. West J Med 148:88-90.

22. Rohde CM, Manatt M, Clagett-Darne M, et al. 1999. Vitamin A antagonizes the action of vitamin D in rats. J Nutr 129:2246-2250.

23. Ragavan VV, Smith JE, Bilezikian JP. 1982. Vitamin A toxicity and hypercalcemia. Am J Med Sci 283:161-164.

24. Freudenheim JL, Johnson NE, Smith EL. 2005. Relationships between usual nutrient intake and bone-mineral content of women 35-65 years of age: Longitudinal and cross-sectional analysis. Am J Clin Nutr 44:863-76.

25. Melhus H, Michaëlsson K, Kindmark A. 1998. Excessive dietary intake of vitamin A is associated with reduced bone mineral density and increased risk for hip fracture. Ann Intern Med 129:770-8.

26. Feskanich D, Singh V, Willett WC. 2002. Vitamin A intake and hip fractures among postmenopausal women. JAMA 287: 47-54.

27. Moore T, Wang Y. 1945. Hypervitaminosis A. Biochem J 39: 222-8.

28. Mellanby E. 1947. Vitamin A and bone growth: the reversibility of vitamin A deficiency changes. J Physiol 105: 382-99.

29. Fell H, Mellanby E. 1952. The effect of hypervitaminosis A on embryonic limb buds cultivated in vitro. J Physiol 116: 320-49.

30. Armstrong R, Ashenfelter K, Eckoff C, et al. 1984. General and reproductive toxicology of retinoids. In: Sporn MB, Roberts AB, Goodman DS, EDS. The retinoids: Biology, Chemistry and Medicine. $1^{\text {st }}$ ed, v2, Orlando, FL: Academic PR; 287-326.

31. Zimmerman MR. 1990. The paleopathology of the liver. Ann Clin Lab Sci 20: 301306.

32. Bendich A, Langseth L. 1989. Safety of vitamin A. Am J Clin Nutr 49: 358-371.

33. Promislow JHE, Goodman-Gruen D, Slymen DJ, Barrett-Connor E. 2002. Retinol intake and bone mineral density in the elderly: the rancho bernardo study. J Bone Miner Res 17: 1349-58.

34. Chrischilles EA, Butler CD, Davis CS, et al. 1990. A model of lifetime osteoporosis impact. Arch Intern Med 151: 2026-32.

35. Nguyen TV, Eisman JA, Kelly PJ, et al. 1996. Risk factors for osteoporotic fractures in elderly men. Am J Epidemiol 144: 255-263.

36. Johansson S, Lind PM, Hakansson H, et al. 2002. Subclinical hypervitaminosis A causes fragile bones in rats. Bone 31: 685-9.

37. http://www.mod-med.com/1999/fevrier/hypercalcemia.htm (accessed on 21st may 2017). 
38. Ramachandran R. 2001. A programme gone awry. A UNICEF-sponsored mass campaign of vitamin A administration for children in Assam leads to some startling consequences and questions. Frontline 18.

(http://www.frontline.in/static/html/fl1825/18250910.htm)

39. Mannar V, Court A. 2008. Ensuring the quality of vitamin A capsules used in supplementation programs. Am J Clin Nutr 87(5):1539-40. 